\title{
Dockovdia cookarum infection and the prosobranch gastropod Lanistes libycus host in Omi Stream, Ago- Iwoye, south-western, Nigeria
}

\author{
O. M. Agbolade ${ }^{1 *}$, A. B. Odaibo ${ }^{2}$ \\ ${ }^{1}$ Department of Biological Sciences, Olabisi Onabanjo University, P.M.B. 2002, Ago-Iwoye, Nigeria. \\ ${ }^{2}$ Department of Zoology, University of Ibadan, Ibadan, Nigeria.
}

Accepted 31 December 2003

\begin{abstract}
Dockovdia cookarum infection was studied in relation to the abundance and size classes of Lanistes libycus from Omi Stream, Ago-Iwoye, Nigeria, between September 1997 and June 1998. 57.6\% of the 262 $L$. libycus recorded were collected during periods of heavy rainfall. $17.2 \%(45)$ of the $L$. libycus examined had $D$. cookarum infection. The water mite prevalences were higher in rainy season than in dry season, and ranged between $3.0 \%$ and $44.4 \%$ monthly. L. libycus in $21-30 \mathrm{~mm}$ size class had the highest prevalence $(\mathbf{7 3 . 3 \%})$. Intensity of infection was higher in rainy season than in dry season, and ranged between 1 and 6 mite(s)/snail. 2.6\% of the $L$. libycus specimens in the $21-30 \mathrm{~mm}$ size class had concurrent $D$. cookarum and Chaetogaster limnaei infections.
\end{abstract}

Key words: Dockovdia cookarum, water mites, Lanistes libycus, freshwater molluscs, Nigeria

\section{INTRODUCTION}

Some water mites are known to parasitize molluscs at one stage or the other of their life cycle. The majority of these parasitic water mites infest freshwater bivalves, while relatively few are harboured by freshwater gastropods (Gledhill, 1985a, b). Five unionicolid water mites had been associated exclusively with prosobranch gastropod molluscs, including Unionicola (Baderatax) macani Gledhill, 1985 associated with Lanistes ovum Peters from Nigeria (Gledhill and Vidrine, 2002).

Lanistes libycus is a freshwater gastropod mollusc common in West Africa, and widely distributed in southwestern Nigeria (Ukoli, 1989; Brown, 1994). A study of freshwater bodies in Ago-Iwoye in this area revealed the occurrence of a water mite species in the mantle cavity of L. libycus from Omi Stream (Agbolade, unpublished observation). The water mite was recently described as a new genus and species, Dockovdia cookarum by Gledhill

\footnotetext{
Corresponding author. E-mail: agbolmos@yahoo.com.
}

(2002). Gledhill noted that $D$. cookarum was the first water mite species from the family Hygrobatidae to be reported as a parasite of a freshwater mollusc.

This report presents an account of the prevalence and intensity of $D$. cookarum in relation to the abundance and size classes of $L$. libycus from Omi Stream.

\section{MATERIALS AND METHODS}

Study area and sampling site

Ago-Iwoye is located in ljebu North area of Ogun State, southwestern Nigeria, and is the main seat of Olabisi Onabanjo University (O.O.U.). The town lies within the tropical rain forest belt, between latitudes $6^{\circ} 55^{\prime}$ and $6^{\circ} 56^{\prime}$, and longitudes $3^{\circ} 54^{\prime}$ and $3^{\circ}$ $56^{\prime}$. Omi Stream flows through the back of the mini-campus of O.O.U. The stream is frequented by many inhabitants of Ago-Iwoye for purposes such as bathing, laundry, fishing, and edible water snail. The section of the Stream around the back of the mini campus of O.O.U. was chosen as sampling site based on accessibility. Different parts of the sampling site have sandy, muddy or rocky substratum. 


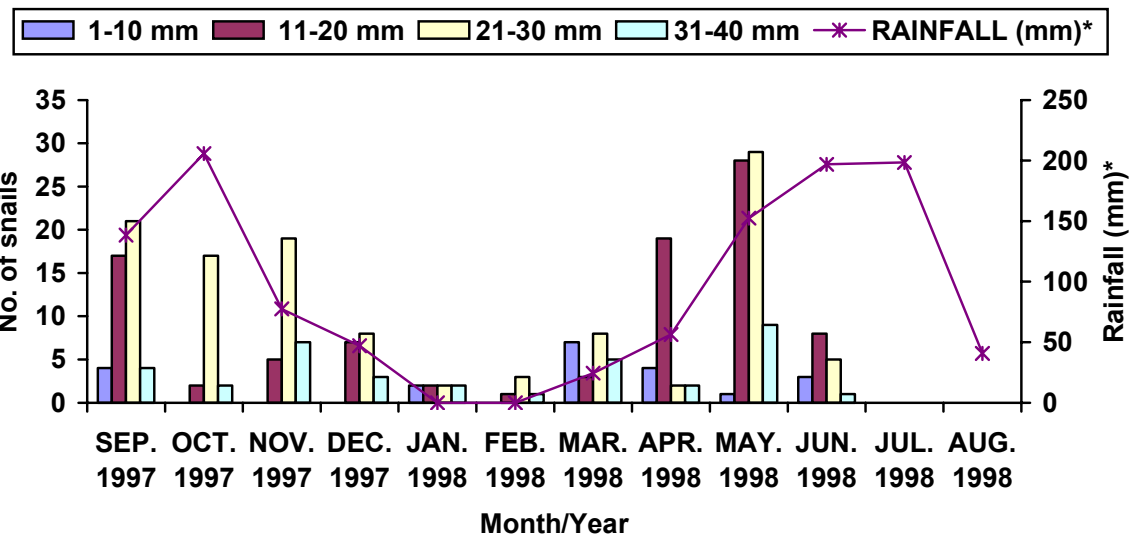

Figure 1. Monthly size distribution of Lanistes libycus from Omi stream and rainfall pattern in the study area. *Source: Federal Department of Meteorological Service.

$\square$ 1-10 $\mathrm{mm} \square 11-20 \mathrm{~mm} \square 21-30 \mathrm{~mm} \square 31-40 \mathrm{~mm}$

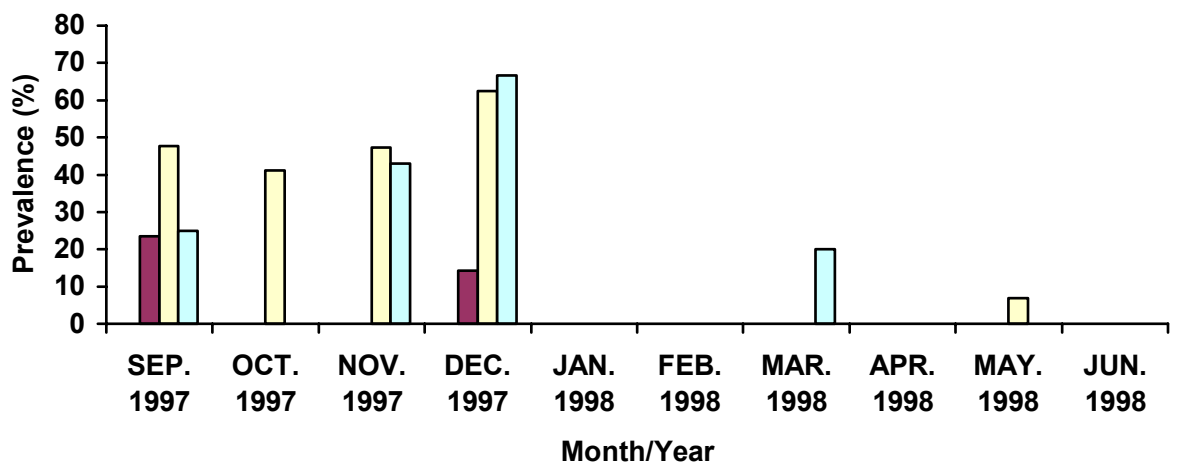

Figure 2. Monthly prevalence of $D$. cookarum infection according to size Classes of $L$. libycus.

\section{Sample collection and examination}

L. libycus sample collection was done from September 1997 to June 1998. During each working visit, sampling was done at different locations of the sampling site for 40 minutes to one hour. This was done using a pair of stainless steel tongs and, sometimes, long-handled scoop.

In the laboratory, the shell height of each L. libycus sample collected was measured with a pair of vernier callipers. The shell was crushed with mortar and pestle. Subsequently, the mantle was dissected in a petri dish containing water and examined for water mites as had been previously described (Fashuyi, 1990). All examinations were done with dissecting microscope.

\section{RESULTS}

A total of 262 samples of $L$. libycus were recorded in this study. Figure 1 gives the monthly size distribution of $L$. libycus from Omi Stream in relation to rainfall pattern. $57.6 \%$ (151) of the snails was collected in September to October 1997 and May to June 1998, which were periods of heavy rainfall. $20.2 \%$ (53) of the snails was collected during period of little or no rainfall (December 1997 to March 1998). Among the four size classes, the abundance of $1-10 \mathrm{~mm}$ size class $(8.0 \%)$ was statistically similar $\left(\chi^{2}=1.50, \mathrm{df}=1, \mathrm{P}>0.05\right)$ to that of $31-40 \mathrm{~mm}$ size class $(13.7 \%)$. Likewise, the abundance of $11-20 \mathrm{~mm}$ size class $(35.1 \%)$ was statistically similar $\left(\left(\chi^{2}=0.90, \mathrm{df}=1, \mathrm{P}>0.05\right)\right.$ to that of $21-30 \mathrm{~mm}$ size class $(43.5 \%)$.

$17.2 \%(45)$ of the $L$. libycus samples collected had $D$. cookarum infection in their mantle cavity. The monthly prevalence of $D$. cookarum infection according to size classes of L. libycus is summarized in Figure 2. In 1997, the total prevalences of infection for September (32.6\%), October (33.3\%), November (38.7\%) and December $(44.4 \%)$ were not significantly different $\left(\chi^{2}=2.43, \mathrm{df}=3\right.$, $\mathrm{P}>0.05)$. In 1998 , the total prevalences of $D$. cookarum infection for March (4.4\%) and May $(3.0 \%)$ were not significantly different $\left(\chi^{2}=0.26, \mathrm{df}=1, \mathrm{P}>0.05\right)$. Among $L$. libycus infected with $D$. cookarum, the prevalences of 
infection among $11-20 \mathrm{~mm}(11.1 \%), 21-30 \mathrm{~mm}$ (73.3\%) and $31-40 \mathrm{~mm}(15.6 \%)$ size classes were significantly different $\left(\chi^{2}=72.18, \mathrm{df}=2, \mathrm{P}>0.05\right)$.

The intensity of $D$. cookarum in infected $L$. libycus specimens examined ranged from 1 to 6 mite(s) /snail. In September to December 1997, 33.3\% of the infected $L$. libycus specimens had 1 mite/snail, while $66.7 \%$ had intensity range of 2 to 6 mites/snail. In March to June 1998, the intensity was 1 mite/snail. The total geometric mean intensity was 1.7 mites/snail. Among the size classes, geometric mean intensities were 1.5 mites/snail for $11-20 \mathrm{~mm}$, and $1.8 \mathrm{mites} / \mathrm{sn}$ ail for both $21-30 \mathrm{~mm}$ and $31-40 \mathrm{~mm}$ size classes.

$6.1 \%(16)$ of the $L$. libycus specimens examined had Chaetogaster limnaei (von Baer) in their mantle cavity. Among $11-20 \mathrm{~mm}, 21-30 \mathrm{~mm}$, and $31-40 \mathrm{~mm}$ size classes, the prevalences of C. limnaei were $3.3 \%, 8.8 \%$ and $8.3 \%$, respectively. The intensity of C. limnaei infection ranged from 1 to $5 /$ snail. Three $(2.6 \%)$ L. libycus specimens in $21-30 \mathrm{~mm}$ size class had concurrent $D$. cookarum and $C$. limnaei infections. One $(0.9 \%) L$. libycus specimen in $21-30 \mathrm{~mm}$ size class had concurrent infections of $D$. cookarum and an unidentified nematode species.

\section{DISCUSSION}

In this study, we observed that L. libycus was more abundant during periods of heavy rainfall than period of little or no rainfall. This was inconsistent with previous reports that some other freshwater snails were more abundant during period of little or no rainfall (Lwambo, 1988). In September to November 1997 and May to June 1998, the water volume and velocity in Omi Stream were high. Many of the L. libycus collected might have been flushed to the sampling site from the upper region of the stream. A sizeable proportion of the snails were attached to fallen leaves (including those of Bambusa sp.), twigs and plants at the brink of the stream. Vegetation had been identified as an important factor influencing the population of freshwater snails (Ukoli, 1984). During period of little or no rainfall, the water volume and velocity were low. Also, fallen leaves and twigs were more abundant than during heavy rainfall season. Ordinarily, these factors ought to have favoured a higher density of $L$. libycus during period of little or no rainfall (Brown, 1994). But, as it had been noted elsewhere for $L$. ovum (Fashuyi, 1990) and L. libycus (Agbolade, 2000, 2002), L. libycus is commonly collected for consumption, especially by children, in the study area. The low water volume and velocity associated with relatively dry period renders numerous parts of the Stream readily accessibly to adults and children for $L$. libycus collection. Conversely, high volume and velocity of water will naturally scare many, especially children, away from the Stream during heavy rainfall season. Moreover, many inhabitants have little or no reason to visit the Stream during heavy rainfall period since water is usually available from some other sources. The foregoing reasons might have contributed to the observed seasonal density of $L$. libycus in Omi Stream. This assertion is further strengthened by the observation that Melanoides tuberculata (Muller) and Potadoma moerchii (Reeve), recorded from the Stream during the study, were more abundant during little or no rainfall period (Agbolade, personal observation). Although snail sampling was not done in July and August 1998, the heavy rainfall recorded in July suggested that $L$. libycus would have had high abundance, at least, in July 1998.

The relative low abundance of $1-10 \mathrm{~mm}$ size class $L$. libycus in this study may be a reflection of their inability to withstand high water velocity during heavy rainfall period. Moreover, during dry period, many $1-10 \mathrm{~mm}$ size class specimens might have been left unnoticed, especially that the rocky substratum of some areas of the Stream seriously hindered successful scooping.

The recorded prevalence $(17.2 \%)$ of $D$. cookarum infection in this study agreed with the opinion that the hygrobatid species is highly adapted for exploitation of $L$. libycus and that there is a long association between them (Gledhill, 2002). L. libycus belongs in the family Ampullaridae (Brown, 1994). The occurrence of $D$. cookarum in L. libycus conformed with previous records of water mite species in some other African prosobranch hosts, which were exclusively ampullarids (Gledhill, $1985 b, 2002)$. The prevalence of $D$. cookarum in $L$. libycus was less than that of $U$. (B.) macani in $L$. ovum from Ajara fish ponds in Badagry (Fashuyi, 1990). Greater dispersion of $D$. cookarum might have been enhanced by the lotic nature of Omi Stream.

The prevalence of $D$. cookarum infection in L. libycus in this study appeared high during heavy rainfall period till the end of rainy season in December, disagreeing with the report of Fashuyi (1990). The relatively few samples of $L$. libycus collected from the peak of dry season to the return of rainy season might have contributed to the low monthly prevalences of $D$. cookarum in this period. The low prevalence and absence of $D$. cookarum infection in May and June respectively, which were periods of heavy rainfall, suggested the possibility of some other influencing factors which require further studies. In this study, $21-30 \mathrm{~mm}$ size class had the highest prevalence of $D$. cookarum infection, and this possibly showed that $L$. libycus in this size class were most susceptible to infection.

The intensity range of $D$. cookarum in $L$. libycus was lower than the range reported for $U$. (B.) macani in $L$. ovum (Fashuyi, 1990). The lotic nature of Omi Stream in contrast to the lentic nature of the ponds studied by Fashuyi (1990) might have contributed to the discrepancy. The intensity of $D$. cookarum seemed generally high in rainy season and low in dry season, in variance with previous reports (Fashuyi, 1990). Possible relative preponderance of the water mites in the Stream 
and the relative ease of their invasion into $L$. libycus during rainy period might have contributed to this observation. In the study area, $L$. libycus also harboured C. limnaei, and an unidentified nematode species, each of which co-existed with $D$. cookarum in some $L$. libycus specimens. C. limnaei had also been reported in $L$. ovum (Fashuyi, 1990).

\section{ACKNOWLEDGMENTS}

We thank Dr. T. Gledhill of Freshwater Biological Association, Cumbria, United Kingdom, who helped to described the water mite. We are also grateful to Miss Tanwa Agbolade for her field assistance, and Mr. Alebiosu of Federal Department of Meteorological Services for providing rainfall data.

\section{REFERENCES}

Agbolade OM (2000). Urinary schistosomiasis and persistent freshwater contact in Mamu, Ogun State, Nigeria. Nig. J. Sci. 34: 41 - 45.

Agbolade OM (2002). Potential human schistosomiasis transmission foci in Oru, Ogun State, Nigeria - A preliminary report. Nig. J. Sci. 36:245-248.

Brown DS (1994). Freshwater snails of Africa and their medical importance. Second Edition. Taylor and Francis Ltd., London.
Fashuyi SA (1990). Occurrence of Unionicola (Pentatax) macani Gledhill (hydrachnellae, acari) in the prosobranch mollusc Lanistes ovum Peters in Ajara Fish Ponds in Badagry, Nigeria. Hydrobiologia 202: $171-174$.

Gledhill T (1985a). Water mites - Predators and parasites. Freshwater Biological Association Annual Report 53: 45 - 59.

Gledhill T (1985b). A new species of water-mite, Unionicola (Pentatax) macani (Unionicolidae, Hydrachnellae, Acari), from the mantle cavity of the prosobranch mollusc Lanistes ovum Peters in Nigeria, with remarks on some aspects of host/parasite relationships between unionicolids and molluscs. Arch. Hydrobiol. 104 : 77 - 92.

Gledhill T (2002). A new genus and species of water mite (Acari : Hydrachnidia : Hygrobatidae) from the prosobranch gastropod Lanistes libycus (Morelet) (Streptoneura : Ampullariidae) in Nigeria. In : Smith IM (ed.).An Acarological Tribute to David R. Cook - From Yankee Springs to Wheeny Creek. Indira Publishing House,Michigan, pp. 75-82.

Gledhill T, Vidrine MF (2002). Two new sympatric water mites (Acari : Hydrachnidia: Unionicolidae) from the mutelid bivalve Aspatharia sinuata (von Martens) in Nigeria with some data on unionicoline bivalve relationships. J. Nat. Hist. $36: 1351-1381$.

Lwambo NJS (1988). Transmission of urinary schistosomiasis in Sukumaland, Tanzania. 1. Snail infection rate and incidence of infection in school children. J. Helminth. 62: 213-217.

Ndifon GT, Ukoli FMA (1989). Ecology of freshwater snails in south western Nigeria. 1. Distribution and habitat preferences. Hydrobiologia $171: 231-253$.

Ukoli FMA (1984). Introduction to parasitology in Tropical Africa. John Wiley and Sons Ltd., Chichester. 